\title{
16
}

\section{Developing information systems for schools of the future}

\author{
C.L. Fulmer
}

Northern Illinois University

Leadership and Educational Policy Studies, 201 Gabel Hall

DeKalb, Illinois, USA

Phone: 815-748-3615

e-mail: p60clf1@wpo.cso.niu.edu

F.P. Frank

Georgia State University

Educational Policy Studies, University Plaza

Atlanta, Georgia, USA

Phone: 404-651-1199

e-mail: ffrank@gsu.edu

\begin{abstract}
This article explores the lack of interface between educators and information systems and highlights the inclusion of teaching and learning variables as key to developing information systems which touch core needs of educators and inform teaching and learning processes. The assumption that more and better training will close the gap between educational need and information system adoption is questioned. The authors argue that information systems will be more readily adopted by educators if systems make teaching and learning variables more central. A model for developing this new generation of information systems is presented.
\end{abstract}

\section{Keywords}

Professional development, educational management, information technology

\section{INTRODUCTION}

Educational information systems have evolved over the last forty years from business management models which are effective for inventory control, personnel management, cost analysis, and audit. Extant educational information systems have reflected these strengths but have tended to be far less effective at depicting the conditions of teaching and learning. Recent information systems serve the purpose of evaluating programs, personnel, or for generating data for accreditation purposes. They have not provided quality data for analyzing and intervening in processes of teaching and learning. We 
explore some reasons why information systems are not being used more extensively in school settings, and why educational leaders have not taken a leadership role in this area in an attempt to reframe arguments for retraining educational leaders. If one holds that an educational leader is a person who has the capacity to assign resources to system needs, he or she is a key person to the invention and application of information systems in the schools. To date, however, educational leaders have not been heavily invested in information systems development. This article outlines the uses of information systems in schools and offers explanation for the lack of interface between educators and information systems.

\section{USES OF COMPUTERS AND INFORMATION SYSTEMS}

A review of the literature provided the following list of uses of information systems for administrative purposes in schools: student records (Barbour, 1987; Crawford, 1985; Haugo, 1981; Naron \& Estes, 1985; Ogletree \& Haskins, 1983; Walters, 1987), staff/personnel records (Bosch, 1988; Crawford, 1987; McIsaac, 1984; Spuck \& Atkinson, 1983), financial management such as budget preparation and financial reports (McIsaac, 1984; Pogrow, 1985; Rolley, 1986), inventory and property records (Crawford, 1987; Haugo, 1981; Pogrow, 1985; Vogt, 1988), student scheduling (Crawford, 1987; McIsaac, 1984; Pogrow, 1985), grade reporting and analysis (Marcum, 1987; McIsaac, 1984; Pogrow, 1985) attendance reporting (Barbour 1987; Haugo, 1981; Spuck \& Atkinson, 1983; Vogt, 1988), media center/library records (Bosch, 1988; Crawford, 1985; McIsaac, 1984; Spuck \& Bozeman, 1988), student transportation (Bosch, 1988; Crawford, 1987; Naron \& Estes, 1985; Walters, 1987), test scoring and records (Barbour, 1987; Naron \& Estes, 1985; Ogletree \& Haskins, 1983), athletic records (Crawford, 1987; Haugo, 1981), student discipline records (Lindelow, 1984), special education/IEP records (Bosch, 1988; Crawford, 1987), instructional management/computer-managed instruction (Spuck \& Bozeman, 1988; Taylor, Cole, Hemenway \& Hillman, 1989; Wagner, 1985), computer-scored examinations (McKenzie, 1984), computer-assisted examination (Brown, 1984; McIsaac, 1984); accessing information from data banks (Crawford, 1985), student guidance (Crawford 1985), energy management (Lindelow, 1984; Pogrow, 1985), and food service operations (Crawford, 1987).

Two studies (Mikulcik, 1993; Tiede, 1992) provide evidence of actual use of information technology by principals. The principals studied were high-end users who would be most likely to apply those systems to pedagogically related decision making. The researchers found that actual use does not measure up to the promise of information system applications. According to Mikulcik (1993) and Tiede (1992), principals claimed that they were self-trained through trial and error, or took computer workshops or computer classes at vendor sites. Their formal preparation programs did little to provide them with the requisite computer skills. Computer integrated course work was absent from their preparation programs. Each researcher investigated principals' computer usage for system tasks (record keeping, correspondence and communications, monitoring student progress, and other building management) and found that principals used the computer in order of preference: correspondence, communications, student progress/classroom grades, test data, and discipline records. Mikulcik (1993) and Tiede (1992) recommended that actual computer usage would increase when principals received further training. 


\section{THE ISSUE OF ADMINISTRATOR TRAINING}

Typically, administrator training in IT (Fulmer, 1990) has been handled in three ways: (a) require students to provide evidence of computer skills before admitting them to the programs, (b) require students to take a computer competencies course, or (c) require preparation programs to develop computer integrated curricula through which students can acquire computer competencies (Frank, Fulmer, \& Mackett, 1991; UCEA, 1993a, $1993 \mathrm{~b})$. While it would be hard to argue against more or better computer training for administrators, it is our position that the training failure is, in part, the outcome of lack of perceived usefulness of information systems. Put most simply, those who see a tool as being central to success will be highly motivated to master the use of the tool. We argue that the lack of perceived usefulness of information systems is rooted in the comparative absence of information systems which focus on the dynamics of teaching and learning in the classroom. Put another way, educational leaders and teachers who are not very skilled at conceptualizing or using information systems do not perceive a fit between information systems and their everyday needs and are disinclined to invest energy in learning. In Roger's (1983) stages of acquiring an innovation, the most critical juncture in the process is when people decide to adopt the innovation. As teaching and learning are honored in information systems, the training issue will disappear or be reshaped as educators become serious adopters.

\section{RECONCEPTUALIZING THE PROBLEM}

We assert that an alternative to training educators to use systems that do not meet their core needs is to help them generate and use a system that does. Such a system will offer educators meaningful use of information system technology and fundamentally alter the way people are trained to use it.

\subsection{Etic/Emic origins of information systems}

We are using the paired phrase emic-etic to denote an approach to information system development. From the ethnographic tradition, frameworks constructed from inside an organization are termed emic and frameworks constructed from outside that organization and juxtaposed on that environment are termed etic. Educational information systems based on traditional management thinking would tend to be etic systems and educational information systems based on processes of teaching and learning would tend to be emic systems. Most systems in education were adapted from management thinking because we have more often been interested in evaluation of people and programs. Further, the complexity of inventing new teaching and learning focused information systems has been daunting. As an example, educators themselves have tended to value more highly and therefore invest more time in normed measures; normed measures have dominated even the emically generated systems (Lemann, 1995a, 1995b).

\subsection{The importance of variables about teaching and learning}

In the interest of illustrating this point we show in Figure 1 a hypothesized evolution of the applications of three kinds of information systems over the last forty-five years. The projection points are based on our experience in the field and illustrate our sense of how this technology has evolved. We assert that management data has had the highest priority and the highest application. As a result, its potential for affecting decision making in educational organizations has been most fully explored. This is also true of normed achievement data which has been almost equally explored. In both of these 
cases, norms, operational procedures, and supporting technology have slowly but surely evolved to support decision making. In the case of both management data and normed achievement data, analyzing data for purposes of decision making were similar to those being used in business and other social enterprises. Persons with linear mind sets pursued with all good intention the etic frameworks they brought to their understanding of the educational enterprise. In these cases, information system developers exploited with great success the potential of information technology to inform their work.

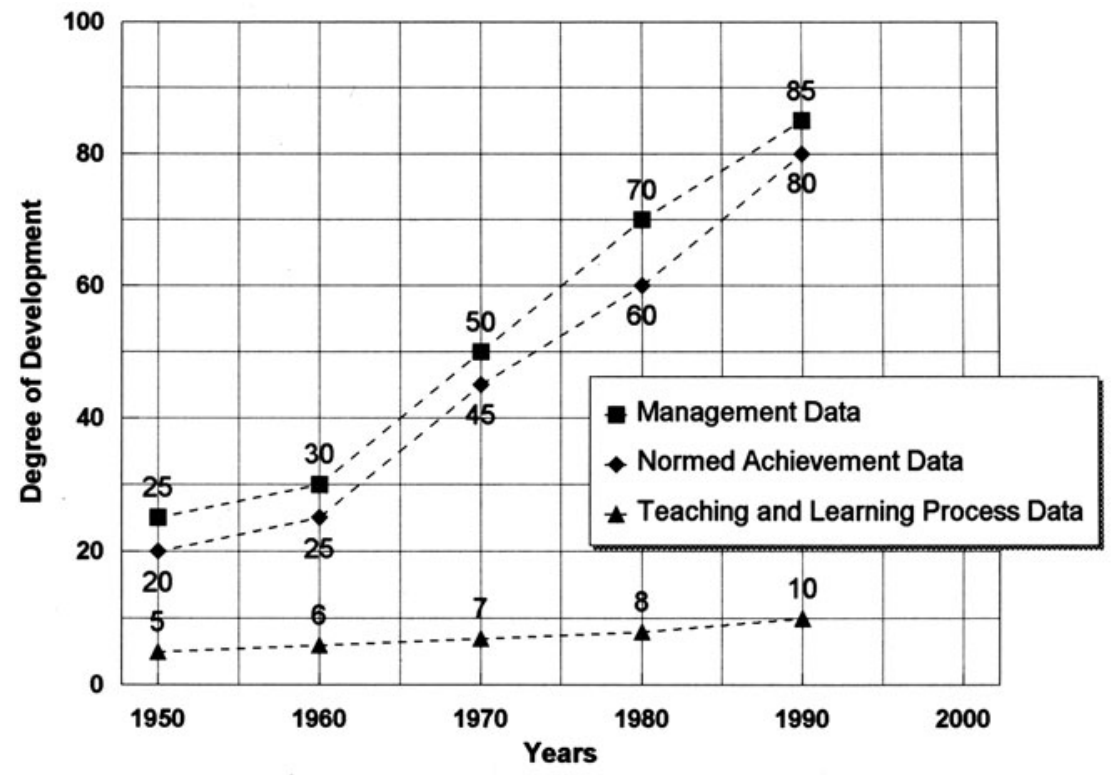

Figure 1 Hypothesized developmental gains on three dimensions on information systems applications in education. 
Evolution of the teaching and learning process data into a viable information system required starting from a more primitive beginning. In fact, there was essentially no parallel usage in business, and therefore there was nothing for educators to borrow. A focus on teaching and learning variables has been comparatively absent during the last forty years of evolution of information technology.

\subsection{Georgia's state wide student information system}

For purposes of illustrating the comparative absence of teaching and learning data in information systems we refer to a system currently in use in the state of Georgia for monitoring data in K-12 educational systems. The state-wide student information system recently established by statute contains 421 variables centered on each child in the system. These data elements are collected around three broad categories. Of the 421 variables, 137 are devoted to the child's surroundings outside the school building such as school system where student resides, English proficiency, bus route, parent/guardian name, and emergency phone. The next major category is composed of 134 variables which deal with the conditions and surrounds of the child's in-school experience such as advisor code, bus route mileage, reason for summer school, course grade received and parent-teacher conferences. The next major bank of 150 variables are scores on normed and criterion referenced achievement tests such as math, writing, Iowa Test of Basic Skills, Grade level tests of achievement and proficiency, and American Collegiate Test. Of the 421 variables only 8 could be classified as teaching and learning variables such as perceptual orientation. We believe that these systems are insufficient rather than wrong minded.

\section{CLOSING THE GAP}

As these three types of information systems (management data, normative achievement data, and teaching and learning process data) are integrated, the relationship between variable banks will be explored. This will accelerate development and produce integrated information systems. Ironically, this emphasis on emically created variable systems is also part of the latest developments in information systems in business (Frank, Mackett, \& Abrams, 1988; Fulmer, 1995). Schuler and Namioka (1993) give examples from around the world of developmental systems in industry using the world of the end user/worker/practitioner as a source for analyzing production problems. This is a significant development in management thinking about information technology in the work place. Similarly, Newberg (1995) has held that the greatest gains in achievement variance are produced by a system where teachers provide continual support. The core of the method he describes for the support is in the rich knowledge that teachers bring to the understanding of the teaching and learning experience of each child over time. In Newberg's model, normed achievement scores are but a thoughtful counterpoint to the more significant work of teachers involved directly with children.

An integrated system should link up a range of data that at its lowest level starts with the learning processes of individual children in classrooms and expands child by child, group by group, school by school, district by district to aggregated data required for state, national, or international analysis. This type of system must have multiple ports of input and output and multiple levels of analysis (Fulmer, 1995). This task is within reach. The hardware capacity and the potential for software development exist. Knowledge of teaching and learning processes and sound pedagogy are well documented. The power of information systems are evident for impacting systems, educational or otherwise. The remaining problem is that developmentally, the worlds of educators and the realities of existing information systems are immature and not well integrated. 


\section{CREATING THE INTERFACE}

In our view, the educational information systems of the future will be developed from data gathered in the following activities. First, a vision of teaching/learning driven educational information systems must be developed through a dialogue with the following participants: teachers, administrators, state, national, and international organizational representatives, and developers of existing educational information systems. Diversity of knowledge and technical expertise are needed in this effort. Second, an audit should be conducted in the following areas: existing information systems, existing data management strategies of teachers, data currently required at various organizational levels, kinds of data required at all instructional levels, and types of data required at all instructional levels. Current formation systems have valuable structures that need not be reinvented. However, an analysis of extant systems would yield both common and missing components. Discovering all the kinds of data required by age level and subject matter as well as the types of data (narrative, biographical, journal, and anecdotal data) are indispensable for building a useful information system. The third step would be that technological and data analysis experts would deal with interface problems. Data already in the system have to be compatible with new data coming into the system. Microcomputer and mainframe compatibility is a must. Interfacing with the practitioner/end user is also a must. The fourth step would be to implement the newly created system in several school districts or educational organizations. The purpose would be to test the usefulness of the system and to initiate cycles of revision. To do so, such a system must model both linear dynamism and temporal immediacy: Linear dynamism is the capacity of a linear system to evolve at the hands of the end user. Temporal immediacy refers to the capacity of a system to provide timely answers for users in educational settings. Day to day educational decisions can not wait for quarterly and yearly data reports. The system must be manipulable from multiple levels, starting at the classroom level. The final step would be to fine tune the system's responsiveness to the ongoing needs of education organizations over several years. Care should be taken that an emically generated system not be inflexible and mimic an etic system.

\section{PROPOSED ACTION PLAN}

The following is an action plan that school district partners could follow to develop the information systems described above.

1. Audit existing educational information systems, variable taxonomies and data analysis protocols being used throughout the United States and elsewhere (Israel, New Zealand, Australia and Canada have invested in this work). Elements in the audit will be variables collected, data record layout, data analysis procedures, software used, confidentiality, units of analysis, sampling, access time delay before data are available for classroom or building use, accuracy of data, compatibility of data sets, display screens, size or comprehensiveness of data sets.

2. Form a cadre of five interested school districts to provide access to their information systems and whose personnel will provide input and clinical settings. Work groups will be formed (e.g. classroom teachers, counselors, principals, special education teachers) in schools of each system. District partners would participate in the development of information systems and provide a setting for BETA testing of new systems. 
3. In each participating school, a staff development trainer should work with a project researcher to define needs and indicators of meeting those needs. Qualitative research methodology is used to document the process and give further clarification.

4. Data obtained from all project researchers and staff development trainers should be used by the researchers to create models of analysis that will help teachers and administrators begin to decode achievement and behavior patterns at the individual student level. Analysis protocols can also be generated at the classroom, grade, and school levels.

5. Researchers should work with teachers and administrators to explore ways to plot teaching and learning patterns over time. Protocols for the analysis of multi-year data should be generated to show the long term patterns of individual student growth and behavior. Long-term analysis offers a way to look at teacher effectiveness and pedagogy over time.

6. Functional data collection instruments will be assembled in an encyclopedia for the use of all educators participating in the development of the system. This encyclopedia would continue to expand with continued work on the system.

7. Researchers and educators will continue to further revise and update the information system.

\section{CONCLUSION}

In sum, more or better training for administrators is not a complete answer to the problem of the lack of interface between educators and information systems. While the literature contains many references to the uses of information systems in educational organizations, research findings report the actual use of information systems by even high-end users falls far short of data analysis for decision making. We have argued in this paper that the problem of lack of use of information systems can not be attributed solely to poor training, but rather that the systems are not meeting a core need. We view this problem as developmental in nature. A process that includes the needs of educators engaged in processes of teaching and learning in the design of information systems, will insure the increased use of information systems. Educators and information systems experts who are able to integrate the realities of educational learning environments and the capacities of information systems will construct responsive information systems and participate in their natural evolution.

\section{REFERENCES}

Barbour, A. (1987) Office romance: why administrators are hooked on technology. Electronic Learning, 6(7), 18-23.

Bosch, K.A. (1988) A microcomputer literacy training model for school administrators. Journal of Research on Computing in Education, 20, 331-8.

Brown, D.T. (1984) Automated assessment systems in school and clinical psychology: present status and future directions. School Psychology Review, 13, 455-460.

Crawford, C.W. (1985) Administrative uses of microcomputers, Part I: needs evaluation. NASSP Bulletin, 69(480), 70-3.

Crawford, C.W. (1987) Administrative uses of microcomputers. The Practitioner, 13(3), 1-12.

Frank, F., Fulmer, C. and Mackett, M. (1991) An open challenge to the field of educational administration to mainline information technology: a town meeting to 
bring together technophobes, techno-indifferents, and technophiles. A town meeting conducted at the annual meeting of the University Council for Educational Administration, Baltimore, Maryland.

Frank, F., Mackett, M. and Abrams, P. (1988) Microcomputers-based information systems and management of student achievement: A description of a working model. Journal of Information Resources Management, 1(2), 37-55.

Fulmer, C.L. (1995) Maximizing the potential of information technology for management: Strategies for interfacing the technical core of education, in Information Technology in Educational Management (eds. B. Z. Barta et al.), Chapman and Hall, London.

Fulmer, C.L. (1990) The integration of micro-computer applications in educational administration curricula. An unpublished dissertation, The Penn State University, University Park, Pennsylvania.

Haugo, J.E. (1981) Management applications of the microcomputer: Promises and pitfalls. ADES Journal, 14, 182-8.

Lemann, N. (1995a) The structure of success in America. The Atlantic Monthly, August 1995, 41-60.

Lemann, N. (1995b) The great sorting. The Atlantic Monthly, September 1995, 84100.

Lindelow, J. (1984) Microcomputers in the school office: primer for administrators. Management Digest Series No. 30, Eugene. (ERIC Document Reproduction Service No. ED 248 571).

Marcum, D. (1987) Putting your school on line: Problems and benefits. NASSP Bulletin, 71(495), 110-2.

McIsaac, D.M. (1984) Managing school information systems (second of a three part series). AEDS Journal, 23, 20-21.

McKenzie, G.D. (1984) Using microcomputers to increase productivity in academia. Journal of Geographical Education, 32, 171-175.

Mikulcik, P.J. (1993) A study of selected junior high/middle school principals use of computers for administrative purposes. An unpublished doctoral dissertation, Northern Illinois University, DeKalb, Illinois.

Naron, N.K. and Estes, N. (1985) Technology in the schools: Trends and policies. A paper presented at the Annual Meeting of the American Education Research Association, Chicago. (Eric Document Reproduction Service No. ED 262-775).

Newberg, N.A. (1995) Clusters: Organizational patterns for caring. Phi Delta Kappan, 76(9), 713-7.

Ogletree, E.J. and Haskins, T.C. (1983) A survey of microcomputer use in Illinois schools. National Institute of Education, Washington, DC. (ERIC Document Reproduction Service No. ED 252189.

Pogrow, S. (1985) Administrative uses of computers: what is the ideal system? NASSP Bulletin, 69(485) , 45-50.

Rogers, E. (1983) Diffusion of innovation (3rd ed.). Free Press, New York.

Rolley, M. (1986) Administrative uses of computers in elementary schools. Paper presented at the annual meeting of the National Catholic Education Association, Anaheim, CA. (ERIC Document Reproduction Service No. ED 268 661)

Schuler, D. and Namioka, A. (1993) Participatory design: principles and practices. Lawrence Elbaum Associates, Hillsdale, NJ.

Spuck, D.W. and Atkinson, G. (1983) Administrative uses of the microcomputer. AEDS Journal, 17(1-2), 83-90.

Spuck, D.W. and Bozeman, W.C. (1988) Training school administrators in computer use. Journal of Research on Computing in Education, 21(2), 229-236.

Taylor, B.L., Cole, D.W., Hemenway, M.W. and Hillman, G.L. (1989) Computer use in curriculum development and curriculum management. Educational Technology, 29(4), 49-51. 
Tiede, L.J. (1992) A study of selected elementary school principals' use of computers for administrative purposes. An unpublished doctoral dissertation, Northern Illinois University, DeKalb, Illinois.

UCEA (1993a) Update: UCEA computer simulation project. UCEA Review, 34(1), 14.

UCEA (1993b) UCEA IESLP project takes off. UCEA Review, 34(4), 1.

Vogt, J. (1988) The amount of principal and secretarial use of microcomputers in elementary schools and principals' perceptions of the actual and ideal importance of selected administrative tasks. Unpublished doctoral dissertation, Northern Illinois University, DeKalb, Illinois.

Walters, D.L. (1987) $P C^{\prime} s$ and the principalship. Paper presented at the annual meeting of the University Council for Educational Administration, Charlottesville, VA. (ERIC Document Reproduction Service No. ED 293 193).

Wagner, W. (1985) Computer-managed instruction: how teachers and principals can improve learning. NASSP Bulletin, 69(478), 22-27.

\section{BIOGRAPHIES}

Professor Fulmer earned her Ph. D. in Educational Administration at The Pennsylvania State University, University Park, Pennsylvania, USA. Currently, she is an Associate Professor in the Department of Leadership and Educational Policy Studies at Northern Illinois University and serves as the Faculty Chair for the Educational Administration and School Business Management program. Connie's research has focused on redefining teaching and learning environments to include pedagogical-based processes and the integration of technology into educational administration curricula.

Professor Frank earned his Ph. D. in Education Administration at the State University of New York at Buffalo, New York, USA. Currently, he is Professor in the Faculty of Educational Leadership and Chair of the Department of Educational Policy Studies at Georgia State University, Atlanta, Georgia, USA. Fred's research has focused on the development of school based information systems and data analyses for informing teaching and learning environments. 